\title{
The stability of impacted morsellized bone grafts in a metal cage under dynamic loaded conditions: an in vitro reconstruction of a segmental diaphyseal bone defect
}

\author{
Pieter H. J. Bullens • Bart H. W. Schreuder • \\ Maarten C. de Waal Malefijt • Rene P. H. Veth • \\ Pieter Buma $\cdot$ Nico Verdonschot
}

Received: 13 August 2007 / Published online: 3 February 2009

(C) The Author(s) 2009. This article is published with open access at Springerlink.com

\begin{abstract}
Introduction Reconstructions of segmental diaphyseal bone defects with massive allografts are related to complications like nonunion and fractures. A reconstruction of these defects with a cage filled with an impacted morsellized bone graft could be an alternative. The bone graft in these cages should ideally be loaded to prevent resorption. Loading of morsellized bone grafts however can cause instability. The goal of this study was to assess the stability of an impacted morsellized bone graft in a cage under dynamic loaded conditions in an in vitro reconstruction of a segmental diaphyseal bone defect. The second goal was to assess the influence of cage type, washing of the graft and bone-cage fit.

Materials and methods Two different cage types were filled with impacted morsellized bone graft. The grafts were used washed and unwashed and in variable bone-cage fit conditions. We recorded the bone graft deformation in the cage under dynamic loaded conditions.

Results Stability appeared to be not very sensitive to the cage type and whether the bone chips were washed or not. However, quality of the fit of the cage with the bone segment was an important parameter and should be optimized during surgery.

Conclusions Morsellized impacted bone graft in a cage is stable in dynamic loaded conditions in an in vitro reconstruction of a segmental diaphyseal bone defect. We believe
\end{abstract}

P. H. J. Bullens $(\varangle) \cdot$ B. H. W. Schreuder

M. C. de Waal Malefijt · R. P. H. Veth .

P. Buma $\cdot$ N. Verdonschot

Orthopaedic Research Laboratory and Department of Orthopaedic

Surgery, Radboud University Nijmegen Medical Centre,

9101, 6500 HB Nijmegen, The Netherlands

e-mail: P.Bullens@ orthop.umcn.nl; pbullens@ hotmail.com that this method of reconstruction is a promising alternative for the reconstruction of large diaphyseal bone defects and should be tested relative to its biological merits in animal experiments.

Keywords Washing $\cdot$ Fit $\cdot$ Nail $\cdot$ Cage $\cdot$ Stability

\section{Introduction}

Large diaphyseal bone defects can be the result of trauma, osteomyelitis and resection of bone tumors. These segmental defects are often reconstructed with structural cortical allografts, which provide initial mechanical strength [15, 17]. However, in-growth of these structural cortical bone grafts is limited and is therefore associated with long-term problems like nonunion and fatigue fractures. These complications result in survival rates of only $64-76 \%$ after 10 years $[7,9,29]$. In two case reports an alternative method of reconstruction was described using cylindrical metal cages filled with morsellized bone graft combined with intramedullary fixation [8, 21]. A study analyzing retrievals of failed spinal cage reconstructions reports only $30 \%$ viable bone in the cages [26]. This could be caused by stress shielding of the cage. Bone grafts incorporate without load due to a trauma response. However, in the long term, load seems to be another important factor in bone healing by stimulating bone remodeling and maintaining bone quantity and quality $[10,18]$. If the load is absent the bone will degrade over time; but if the bone is loaded, studies with morsellized bone grafts in reconstructions have shown that it remodels into healthy bone [16, 22, 23]. It is our aim to reconstruct segmental diaphyseal defects with a cage that contains bone grafts which are mechanically loaded and hypnotized that clinical results can thereby be improved. 


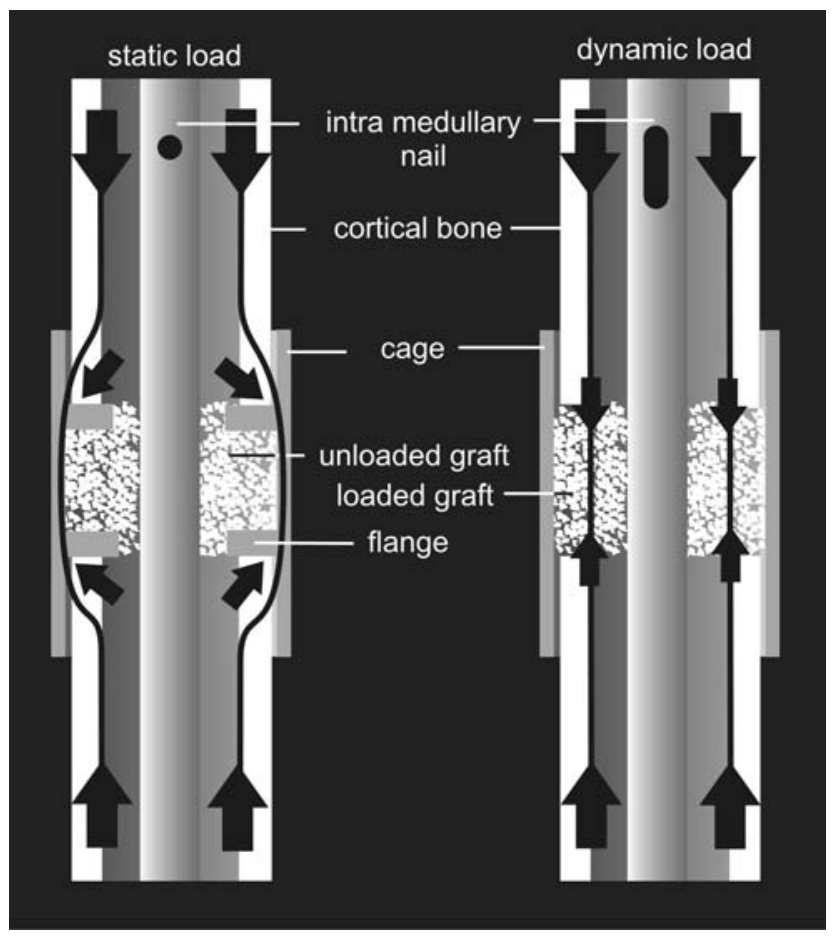

Fig. 1 Loading patterns in a static and dynamic reconstruction

The graft in the diaphyseal cage reconstruction of Cobos [8] could be loaded by removing the load-transfer to the cage and facilitate load-transfer directly to the morsellized bone graft (Fig. 1). This is achieved by allowing the cortical host bone to rest on the graft instead of the cage. The reconstruction could be stabilized with a dynamized intramedullary nail instead of a statically locked nail. Obviously the morsellized bone graft needs to provide stability, which can be achieved by impaction, and could subsequently carry a large portion of the dynamic in vivo load. The question of this study was if an impacted morsellized bone graft in a cage would be stable enough under dynamic loading conditions in an in vitro reconstruction. Deformation of the graft should not exceed $6-10 \mathrm{~mm}$, which is the dynamic range of the slotted holes in commercial intramedullary nails, which is obviously limited to prevent leg length discrepancy. More specifically we assessed the effects of two different cage types, washing of the bone grafts (which could have an effect on the stability properties of the bone grafts), and mismatch between the fit of the circular cage and the irregular host-bone (containment) on the stability of the reconstruction.

\section{Materials}

We tested four groups with three variables; cage type, preparation of the graft (standard or washed) and bone-cage fit (Table 1).
Table 1 Variables of the test groups

\begin{tabular}{llll}
\hline Group 1 & Group 2 & Group 3 & Group 4 \\
\hline Harms cage & Mesh cage & Harms cage & Harms cage \\
Unwashed graft & Unwashed graft & Washed graft & Unwashed graft \\
Contained fit & Contained fit & Contained fit & Uncontained fit \\
\hline
\end{tabular}

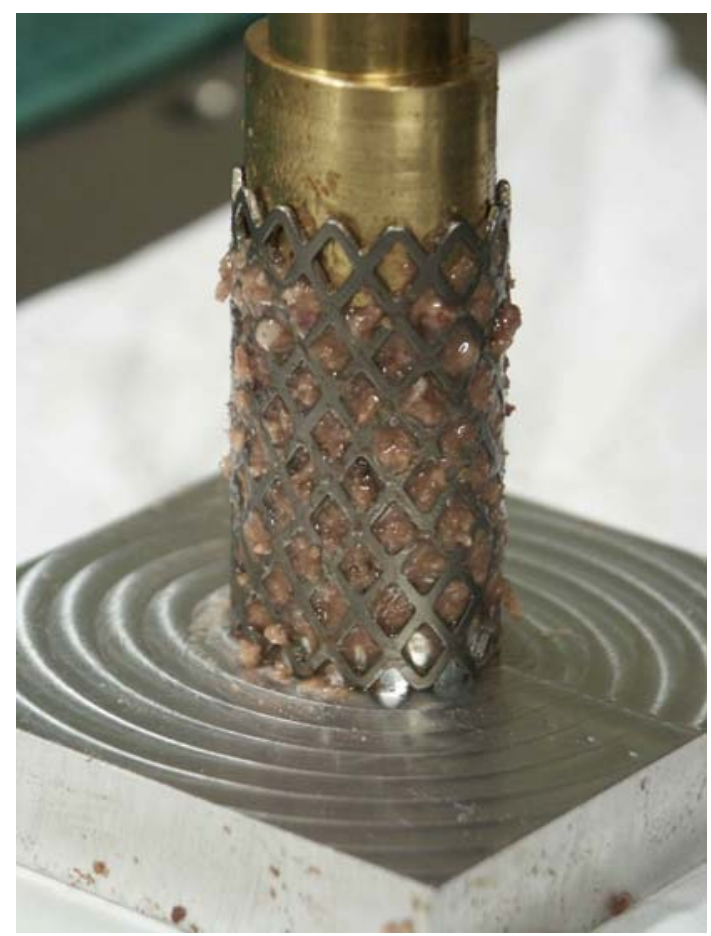

Fig. 2 Harms cage filled with bone graft in a contained and loaded condition

Two types of cages were used in this study. The first cage was a prefabricated titanium Harms cage, commonly used for spinal applications but with potential application possibilities to reconstruct segmental bone defects (DePuy Motech, Warsaw, IN, USA). The height of the cage was $4.5 \mathrm{~cm}$ and it was ellipse-shaped (diameter of $22 \times 28 \mathrm{~mm}$ ) and had a pore size of $4 \times 6 \mathrm{~mm}$ (Fig. 2). The second cage was a stainless steel mesh, commonly used for reconstructions in hip revision surgery (Stryker Howmedica X-Change system, Newbury, UK), which was cut to a height of $4.5 \mathrm{~cm}$ and folded into a cylinder with a diameter of $24 \mathrm{~mm}$. This mesh was fixed with three cerclage wires (Fig. 3) and deformed by hand to a diameter of $22 \times 28 \mathrm{~mm}$. The mesh had a pore size of $3 \times 3 \mathrm{~mm}$.

The morsellized bone graft used to fill the cages was harvested from a fresh frozen bovine distal femur. The distal femurs were sectioned longitudinally into two parts, and the cartilage and cortical bone were removed. Cancellous bone was nibbled by hand using a rongeur that produced large pure cancellous bone chips. The bone chips were 


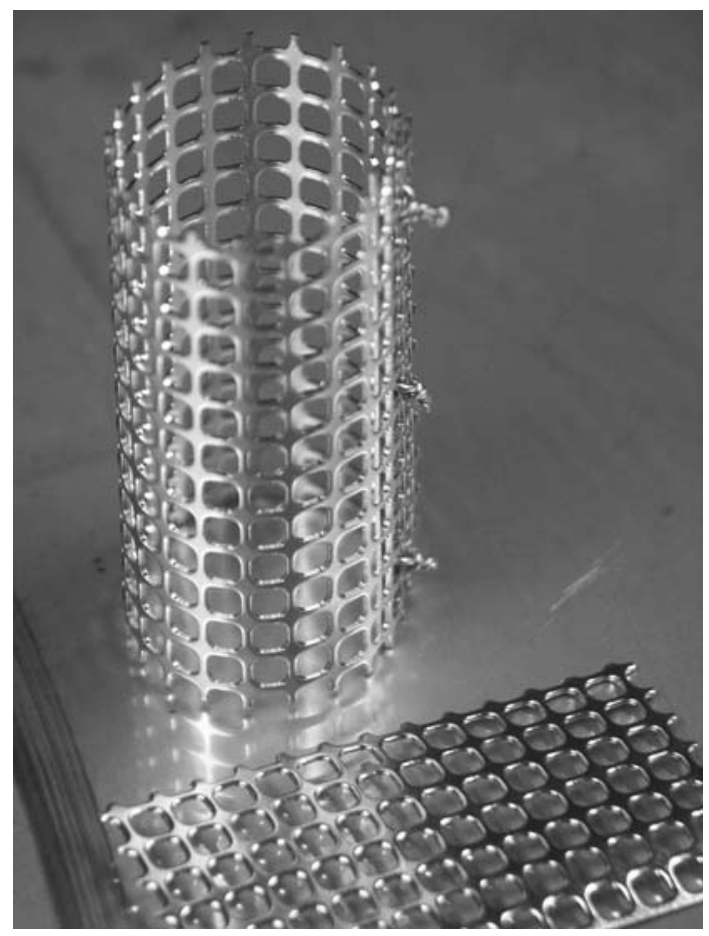

Fig. 3 Stryker mesh cage

subsequently processed in a Noviomagus bone mill (Spierings Medische Techniek, Nijmegen, The Netherlands) with the smallest rasping blade leading to a particle size of about $2 \mathrm{~mm}$. In the group with the washed graft, the graft was washed using 21 of saline with a pulse lavage jet (Stryker, Newbury, UK).

In the last group (Table 1) the graft was loaded with a plunger (cylinder with a $22 \mathrm{~mm}$ outer diameter and $14 \mathrm{~mm}$ inner diameter), which did not completely seal off the cage leaving some space for a possible escape of the graft under load between the plunger and the cage and between the plunger and the intramedullary nail of $10 \mathrm{~mm}$ (Fig. 4). This situation mimics clinical reality where a cage sometimes does not ideally fit around the host bone. In the other groups an ellipse-shaped plunger $(22 \times 28 \mathrm{~mm}$ outer diameter and $10 \mathrm{~mm}$ inner diameter) was used which sealed off the cage and nail leading to a full containment of the graft (Fig. 2).

\section{Methods}

The cages were filled in five layers with a total of $28 \mathrm{~g}$ morsellized bone graft. After each layer 10 standardized impactions were made with a mass of $1.5 \mathrm{~kg}$ (Fig. 5). The mass was dropped from a height of $35 \mathrm{~cm}$. The last layer was followed by 40 impactions of the same weight. After the final impaction the remaining height of the graft layer that was inside the cage was approximately $35 \mathrm{~mm}$. At the

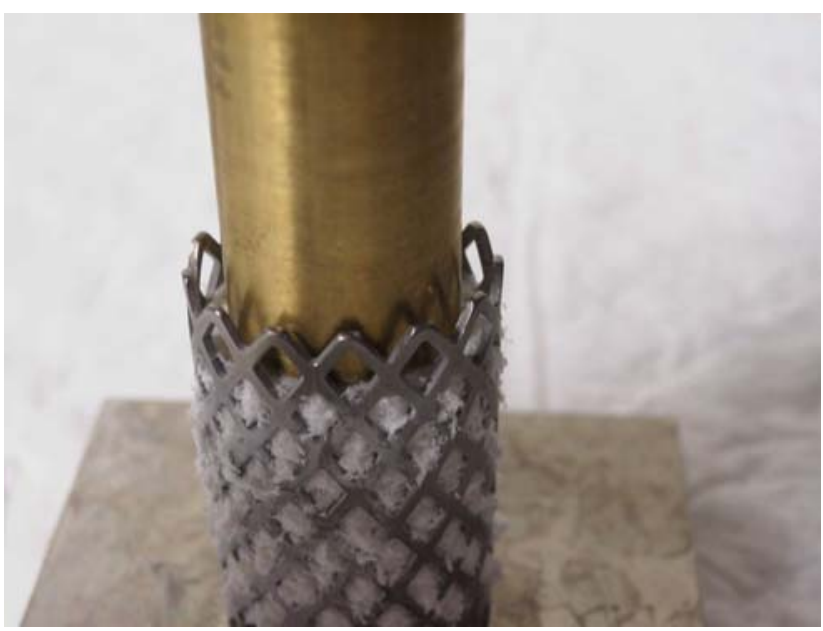

Fig. 4 Mismatch between Harms cage and cylindrical plunger leading to un-containment

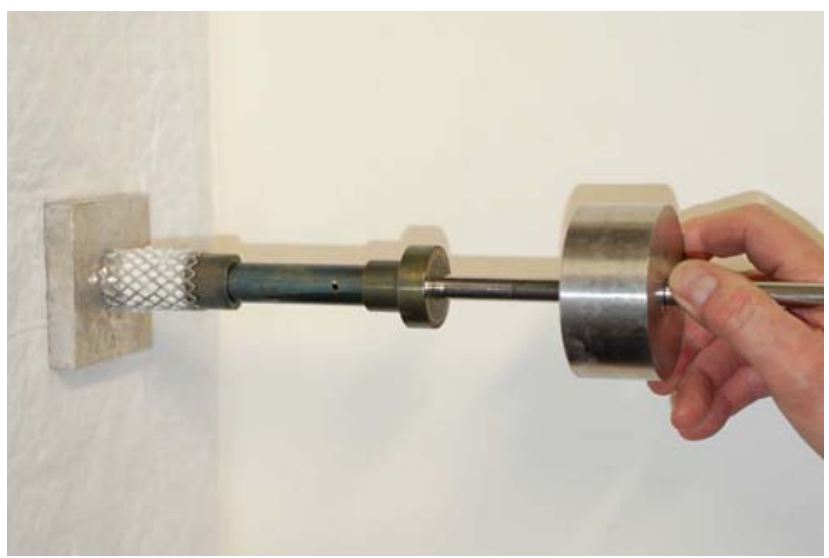

Fig. 5 Impactor with mass of $1.5 \mathrm{~kg}$

center of the grafted cage a $10 \mathrm{~mm}$ thick nail was located to mimic an intramedullary nail (Fig. 6). The graft in the cage was axially loaded using an MTS loading device (MTS Systems Corporation, Minneapolis, Minnesota, USA). An initial preload of 30 Newton was applied to pre-condition the reconstruction. Subsequently a dynamic load was applied with a maximum of $600 \mathrm{~N}$ for a period of 800 cycles and then raised to $1,200 \mathrm{~N}$ for another period of 800 cycles (frequency of $1 \mathrm{~Hz}$ ). During loading, the displacement of the plunger into the graft material was recorded. In each group five cages $(N=5)$ were filled with bone graft and tested according to this protocol.

\section{Statistical analysis}

The ultimate subsidence values, at the end of testing the different groups, were statistically analyzed using ANOVA with a significance level of $P=0.05$. 


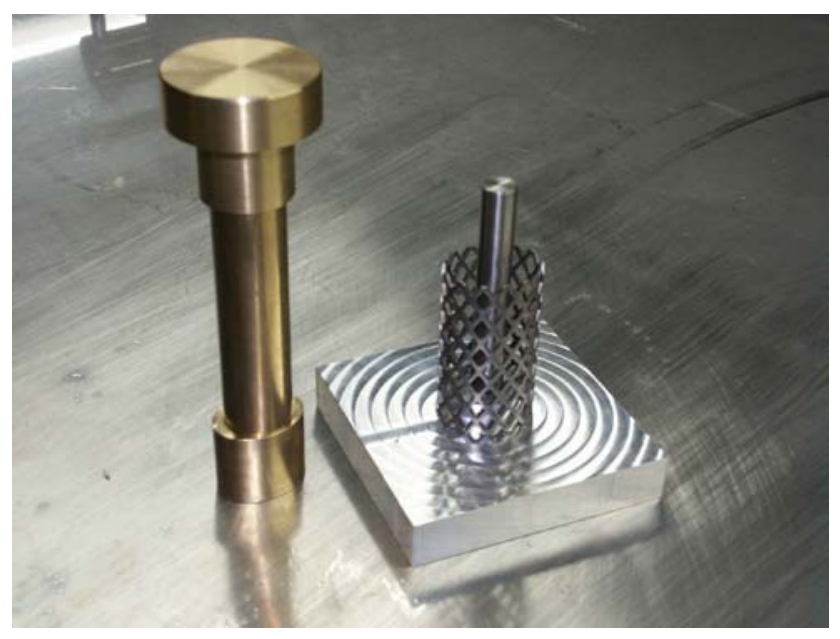

Fig. 6 Impactor and Harms cage with a central nail

\section{Results}

Deformation of the graft material showed a typical visco-elastic/plastic response with a high deformation rate at the beginning of a loading period which leveled off with the number of loading cycles (Fig. 7). During loading, escape of fat through the cage openings was observed. There was no escape of bone graft through the openings of the mesh or the cage. Similarly, we observed no extrusion of bone graft particles at the locations of uncontained fitting of the cage (group 4).

The cancellous graft had a compacted appearance after impacting and subsequent loading, and was difficult to remove out of the cage and mesh. The cage and mesh deformed showed negligible visible deformation. The cerclage wire around the mesh was strong enough to withstand the loading forces.

The Harms cage and mesh cage, which contained unwashed bone grafts were relatively stable with a maximal average subsidence of $2.90 \mathrm{~mm}$ ( $8.3 \%$ loss of volume) and $4.13 \mathrm{~mm}$ (11.8\% loss of volume) for the Harms cage and mesh cage, respectively. Hence, both reconstructions provided an adequate stability of which the subsidence did not exceed the limit of $6 \mathrm{~mm}$ (Table 2). In terms of stability, the more rigid Harms cage was superior to the mesh cage with deformations that were significantly smaller at both load levels of $600 \mathrm{~N}(P=0.004)$ and $1,200 \mathrm{~N}(P=0.001)$.

Washing the bone grafts had surprisingly little effect on the stability of the reconstruction. Hence, no statistical effect of this parameter on the deformation values was found; at a load of $600 \mathrm{~N}(P=0.981)$ and $1,200 \mathrm{~N}$ $(P=0.882)$.

The stability appeared to be susceptible to the quality of fit between the cage and the plunger. The uncontained unwashed bone graft in a Harms cage was not stable enough and exceeded the compression limit of $6 \mathrm{~mm}$ at a load of $1200 \mathrm{~N}$ (Table 2). The effect of containment of the unwashed graft in the Harms cage was significant at a load level of $600 \mathrm{~N}(P=0.001)$ and $1,200 \mathrm{~N}(P<0.001)$.

\section{Discussion}

Large segmental diaphyseal bone defects are commonly reconstructed using large massive cortical allografts. However,
Fig. 7 Height of the graft column in mm under dynamic loaded condition

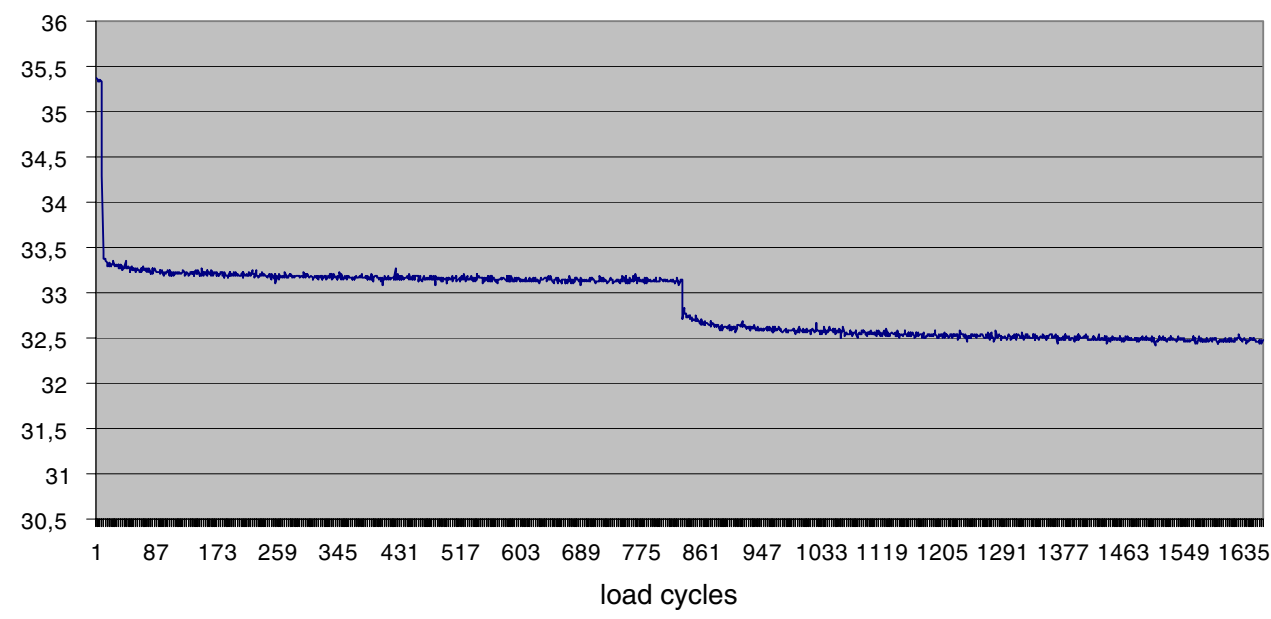

Table 2 Deformation of the graft in $\mathrm{mm}$ under loading

\begin{tabular}{llll}
\hline & Group 1 & Group 2 & Group 3 \\
\hline $600 \mathrm{~N}$ & $2.10 \mathrm{~mm}(1.85-2.41)$ & $3.16 \mathrm{~mm}(2.21-4.83)$ & $2.10 \mathrm{~mm}(1.97-2.25)$ \\
$1,200 \mathrm{~N}$ & $2.90 \mathrm{~mm}(2.64-3.22)$ & $4.13 \mathrm{~mm}(3.12-5.82)$ & $2.95 \mathrm{~mm} \mathrm{(2.81-3.10)}$ \\
\hline
\end{tabular}


incorporation of these grafts is limited and therefore associated with long-term problems like nonunions and failure. Furthermore, they are expensive and carry the risk of transmitting diseases [20]. Therefore alternatives are required. The drawback is that only a small number of publications exist probably owing to the variety of patients with a different diagnosis and stages of diseases making comparison almost impossible [7, 9, 13, 20].

Direct postoperatively cortical grafts obviously have better mechanical properties as compared to morsellized bone graft. However, from a biological perspective the in-growth of a cancellous bone-graft is superior to a cortical bonegraft, which results in a higher incorporation and union rate, and therefore superior long-term characteristics can be expected $[15,17]$.

The reconstruction with a cage containing a loaded bone graft potentially may have adequate biologic features for the morsellized graft and sufficient initial mechanical features owing to a combination of impaction and containment in a cage/mesh [23]. Although the microstructure of the morsellized graft diminishes somewhat after impaction and subsequent loading, it is still less dense than the structural cortical graft which should provide for superior biological properties [6].

The application of structural grafts is also limited by the fact that it is often difficult to obtain an adequate fit between the graft and the host bone. An intimate host graft junction, which facilitates union, is virtually never achieved. The open structure of the cages facilitates in-growth and neovascularization in the large bone defect [5]. However, in-growth can be limited in oncological resections due to the lack of periosteum and adequate soft tissue coverage. A biological reconstruction in these cases especially with adjuvant chemo and radiotherapy is probably difficult to achieve. The intramedullary nail and the cages used (Harms and Stryker mesh) have a proven human application. Therefore, it is likely that the combined use of these materials will not trigger any unexpected adverse biological processes and are in this respect safe to use $[8,23,25]$. An incorporated metal mesh, however, can induce stress shielding in the long term. Resorbable meshes may reduce stress shielding but lack sufficient intrinsic stability to withstand the loads applied.

In this study it was shown that graft stability was influenced by containment. Although the graft was rather stable and forgives some un-containment, this study shows that the cage should fit around the bone optimally in order to maintain an adequate stability.

The stability of the graft may be explained by the fact that the chips of bone graft get entangled after impaction, which increases the inter-particle shear resistance [1, 4]. This is probably the explanation why no protrusion was observed of graft material through the pores in the cages even though the pore size of the cages exceeded the chip size.
The titanium Harms cage is more rigid than the Stryker mesh and consequently shows less deformation when loaded. This probably explains the difference in stability between the two groups. The Stryker mesh, however, can be folded for a custom fit leading to a better fit and consequently a better containment of the bone chips. From that perspective the mesh shows more promise from a surgical point of view, compared to the prefabricated Harms cage.

Washing the graft had little or even a slight negative effect on graft stability in this study. During compression of the unwashed graft fat and blood escaped through the cage openings and therefore adds no relevant extra stability. This is in contrast to studies in which cup stability is increased by graft washing [11, 27]. The difference between cup stability and graft stability in cages could be explained by the fact that containment of the bone chips is far better within the cages with axial loading as compared to the situation around a cup under shear-loaded conditions. Consequently, the stability of the reconstruction becomes less dependent on the inter-particle shear resistance, which is higher in the case of washed particles.

Unloaded grafts are more prone to resorption and could lead to nonunion and migration [26]. Loading of morsellized grafts could lead to instability. However, long-term reports of reconstructions with loaded morsellized graft around an implant do not show instability [16, 23]. Bone grafts in loaded conditions stimulate bone apposition, which could lead to superior results in our reconstruction with bone graft loading instead of load bypassing the graft $[3,24,28]$. To obtain continuous loading of the bone grafts, the deformation of the reconstruction should be less than the range of the dynamization distance of the intramedullary nail. Our goal was therefore that the graft layer would not deform more than $6 \mathrm{~mm}$ after loading. In most study groups this goal was achieved.

The load of $600-1,200 \mathrm{~N}$ was determined as twice the body weight of $60 \mathrm{~kg}$. This weight of a small person is in accordance with the small cage size of $22-28 \mathrm{~mm}$ and should be a reasonable load magnitude for initial loading after reconstruction.

The impacted graft was stable enough if adequate containment could be achieved together with a cage with an adequate intrinsic stiffness. It is realized that stability requires firm impactions. If this is not achieved inferior results have been reported $[2,12,19]$. Relative to in vivo application of this technique, if necessary the dynamic sliding range of the nail could be enlarged to $1 \mathrm{~cm}$ especially in larger defects. This would improve the chances of longterm load transfer from the bone fragments onto the bone chips and should therefore have positive effects on the incorporation of the bone grafts.

Obviously, this study was simplified relative to the clinical reality. An important limitation of this study is the lack 
of in vivo resorption and incorporation of the bone graft. Resorption of morsellized bone graft is followed by replacement of new bone. This could lead to instability during the remodeling phase. This phenomenon needs to be assessed in animal experiments with large segmental defects. The bovine bone used in this study has different properties compared to human bone. The stiffness however is in the same range and is mainly influenced by impaction, particle size and water content $[2,14]$.

Another limitation of the study was the simplified loading configuration. In vivo loading also includes bending and torsion. However, it is expected that the intramedullary nail will transfer these loads, and that owing to the dynamization of the nail, predominantly compressive loads are transferred through the bone grafts. In that sense, the loading configurations seem a good approximation of what occurs in vivo. The indication of the reconstruction with the intramedullary nail and cage is limited to segmental defects in the meta/diaphyseal region of large bones.

We believe that this reconstruction is a promising alternative to the massive cortical grafts in the reconstruction of large diaphyseal defects, and its biological merits need to be assessed in animal experiments with large segmental defects.

\section{Conclusion}

Morsellized impacted bone graft in a cage is stable in dynamic loaded conditions in an in vitro reconstruction of a segmental diaphyseal bone defect. In terms of stability the method appears to be not very sensitive to the cage type and whether the bone chips are washed or not. However, containment of the cage with the bone segment is an important parameter and should be optimized during surgery. If this is achieved, we believe that this method of reconstruction could be a promising alternative for the reconstruction of large diaphyseal bone defects, and its biological behavior needs to be assessed in an animal model.

Acknowledgment The authors wish to thank Willem van de Wijdeven for his technical assistance.

Conflict of interest statement None of the authors have received commercial support related directly or indirectly to the subjects of this article.

Open Access This article is distributed under the terms of the Creative Commons Attribution Noncommercial License which permits any noncommercial use, distribution, and reproduction in any medium, provided the original author(s) and source are credited.

\section{References}

1. Arts CJJ, Verdonschot N, Buma P, Schreurs BW (2006) Larger bone graft size and washing of bone grafts prior to impaction enhances the initial stability of cemented cups. Acta Orthop Scan 77:227-233

2. Bavadekar A, Cornu O, Godts B, Delloye C, Van Tomme J, Banse $X$ (2001) Stiffness and compactness of morsellized grafts during impaction: an in vitro study with human femoral heads. Acta Orthop Scand 72:470-476

3. Benevenia J, Zimmerman M, Keating J, Cyran F, Blacksin M, Parsons JR (2000) Mechanical environment affects allograft incorporation. J Biomed Mater Res 53:67-72

4. Bolder SBT, Schreurs BW, Verdonschot N, Unen JMJ, Gardeniers JW, Slooff TJ (2003) Particle size and method of impaction influence initial stability of cemented cups. Acta Orthop Scand 74:652657

5. Bolder SBT, Schreurs BW, Verdonschot N, Veth RPH, Buma P (2004) Wire mesh allows more revascularization than a strut in impaction bone grafting: an animal study in goats. Clin Orthop Relat Res 423:280-286

6. Bonutti PM, Cremens MJ, Miller BG (1998) Formation of structural grafts from cancellous bone fragments. Am J Orthop 27:499-502

7. Brigman BE, Hornicek FJ, Gebhardt M, Mankin H (2004) Allografts about the knee in Young patients with high-grade Sarcoma. Clin Orthop Relat Res 421:232-239

8. Cobos JA, Lindsey RW, Gugala Z (2000) The cylindrical titanium mesh cage for treatment of a long bone segmental defect. J Orthop Trauma 14:54-59

9. Deijkers RLM, Bloem RM, Kroon HM, Lent JB, Brand R, Taminiau AH (2005) Epidiaphyseal versus other intercalary allografts for tumors of the lower limb. Clin Orthop Relat Res 439:151-160

10. Donk S, Buma P, Verdonschot N, Schreurs BW (2002) Effect of load on the early incorporation of impacted morsellized allografts. Biomaterials 23:297-330

11. Dunlop D, Brewster N, Madabhushi SPG, Usmani AS, Pankaj P, Howie CR (2000) Factors influencing impacted bone grafts strength-to wash or not to wash? Br J Bone Joint Surg 82:S1-S78

12. Eldridge JD, Smith EJ, Hubble MJ, Whitehouse SL, Learmonth ID (1997) Massive early subsidence following femoral impaction grafting. J Arthroplasty 12:535-540

13. Enneking WF, Mindell ER (1991) Observations on massive retrieved human allografts. J Bone Joint Surg 73-A:1123-1142

14. Fosse L, Rønningen H, Benum P, Lydersen S, Sandven RB (2006) Factors affecting stiffness properties in impacted morsellized bone used in revision hip surgery: an experimental in vitro study. J Biomed Mater Res A 78(2):423-431

15. Friedlaender GE (1987) Bone grafts. J Bone Joint Surg 69A:786-789

16. Gie GA, Linder L, Ling RS, Simon JP, Slooff TJ, Timperley AJ (1993) Impacted cancellous allografts and cement for revision total hip arthroplasty. Br J Bone Joint Surg 75:14-21

17. Goldberg VM, Stevenson S (1993) The biology of bone grafts. Semin Arthroplas 4:58-63

18. Lamerigts NMP, Buma P, Huiskes R, Schreurs W, Gardeniers J, Slooff TJ (2000) Incorporation of morsellized bone under controlled loading conditions. Biomaterials 21:741-747

19. Learmonth ID (2003) Impaction grafting of the acetabulum: a universal solution? Orthopedics 26:941-942

20. Lietman SA, Tomford W, Gebhardt MC, Springfield DS, Mankin HJ (2000) Complications of irradiated allografts in orthopaedic surgery. Clin Orthop 375:214-217

21. Ostermann PAW, Haase N, Rubberdt A, Wich M, Ekkernkamp A (2002) Management of a long segmental defect at the proximal meta-diaphyseal junction using a cylindrical titanium mesh cage. J Orthop Trauma 16:597-601

22. Schimmel JW, Buma P, Versleyen D, Huiskes R, Slooff TJ (1998) Acetabular reconstruction with impacted morsellized cancellous allograft in cemented hip arthroplasty. J Arthroplasty 13:438-448

23. Schreurs BW, Bolder SBT, Gardeniers JWM, Verdonschot N, Slooff TJ, Veth RP (2004) Acetabular revision with impacted 
morsellized cancellous bone grafting and a cemented cup. A 15 to 20 year follow-up. Br J Bone Joint Surg 86:492-497

24. Stevenson S, Emery SE, Goldberg VM (1996) Factors affecting bone graft incorporation. Clin Orthop 323:66-74

25. Togawa D, Bauer TW, Brantigan JW, Lowery GL (2001) Bone graft incorporation in radiographically successful human intervertebral body fusion cages. Spine 26:2744-2750

26. Togawa D, Bauer TW, Lieberman IH, Lowery G, Takikawa S (2003) Histology of tissues within retrieved human titanium mesh cages. Spine 28:246-254
27. Ullmark G (2000) Bigger size and defatting of bone chips will increase cup stability. Arch Orthop Trauma Surg 120:445-447

28. Wang JS, Tagil M, Aspenberg P (2000) Load-bearing increases new bone formation in impacted and morsellized allografts. Clin Orthop 378:274-281

29. Zehr RJ, Enneking WF (1996) Allograft-prosthesis composite versus megaprosthesis in proximal femoral reconstruction. Clin Orthop Relat Res 322:207-223 